\title{
Exploiting serological data to understand the epidemiology of foot-and-mouth disease virus serotypes circulating in Libya
}

\author{
Ibrahim Eldaghayes ${ }^{1, *}$, Abdunaser Dayhum ${ }^{1}$, Abdulwahab Kammon ${ }^{1}$, Monier Sharif ${ }^{2}$, Giancarlo Ferrari ${ }^{3}$, \\ Christianus Bartels ${ }^{4}$, Keith Sumption ${ }^{4}$, Donald P. King ${ }^{5}$, Santina Grazioli ${ }^{6}$ and Emiliana Brocchi ${ }^{6}$ \\ ${ }^{I}$ Faculty of Veterinary Medicine, University of Tripoli, P. O. Box 13662, Tripoli, Libya \\ ${ }^{2}$ Faculty of Veterinary Medicine, University of Omar Al-Mukhtar, Albeida, Libya \\ ${ }^{3}$ Food and Agriculture Organization of the United Nations (FAO), Rome, Italy \\ ${ }^{4}$ European Commission for the Control of Foot-and-Mouth Disease (EuFMD), Food and Agriculture Organization \\ of the United Nations (FAO), Rome, Italy \\ ${ }^{5}$ The Pirbright Institute, Ash Road, Surrey, UK \\ ${ }^{6}$ Istituto Zooprofilattico Sperimentale della Lombardia e dell'Emilia Romagna (IZSLER), Brescia, Italy
}

\begin{abstract}
Sporadic outbreaks of foot-and-mouth disease (FMD) have occurred in Libya for almost fifty years. During the spring of 2013, a countrywide serosurvey was undertaken to assess the level of FMD virus circulation and identify FMD virus serotypes in the country. A total of 4221 sera were collected, comprising samples from large ruminants (LR; $\mathrm{n}=1428$ samples from 357 farms) and small ruminants (SR; $\mathrm{n}=2793$ samples from 141 farms). FMD sero-prevalence of NSP antibodies determined by ELISA were $19.0 \%$ (271/1428) with 95\% CI (16.9 - 21.0) and 13.5\% (378/2793) with 95\% CI (12.3 - 14.8) for LR and SR samples, respectively. The sero-prevalence of NSP antibodies in LR was $12.3 \%$ and $19.8 \%$ for age group $<1$ year and $\geq 1$ year, respectively $\left(\mathrm{X}^{2}=4.95, \mathrm{P}=0.026\right)$, while in $\mathrm{SR}$ was $3.7 \%$, $13.6 \%$ and $21.3 \%$ for age group $<1$ year, $1-2$ year and $>2$ year, respectively $\left(X^{2}=118.1, P=0.000\right)$. These observed NSP serologic profiles support the hypothesis of an endemic level of FMD circulation in Libya. All positive sera were tested for SP antibodies for O, A and SAT-2 FMD virus serotypes. Serotype O was the dominant circulating serotype followed by serotype A, while evidence of SAT-2 was not found. These data provide an insight into the wider epidemiology of FMD in Libya, and contribute to field and laboratory investigations that during 2013 serotype $\mathrm{O}$ (O/ME-SA/Ind-2001 lineage) was isolated from clinical samples collected from the country.

Keywords: Foot-and-mouth disease, Large ruminants, Libya, Sero-prevalence, Small ruminants.
\end{abstract}

\section{Introduction}

Foot-and-mouth disease (FMD) is a highly contagious disease caused by FMD virus (FMDV), which belongs to the Picornaviridae family, genus Aphthovirus. FMDV has seven serotypes: O, A, C, Asia 1, SAT-1, SAT-2 and SAT-3 (OIE, 2012). FMD is known to be present in Libya, and periodic outbreaks have occurred since 1959 (Samuel et al., 1999). As reported in the molecular epidemiology/genotyping reports of the World Reference Laboratory (WRLFMD; The Pirbright Institute, UK) only three serotypes have been confirmed in Libya: O (since 1959 and many following years until 2013), A (1979 and 2009) and SAT-2 (2003 and 2012) (Samuel et al., 1999; Knowles et al., 2016; WRLFMD, 2016). Libya currently is qualified in stage 1 of the Progressive Control Pathway (PCP-FMD) (FAO-OIE, 2012).

Following a huge number of FMD outbreaks in 2012 all over the country, mass vaccination was introduced in Libya by the end of 2012 using inactivated purified vaccine (Merial@) against serotypes $\mathrm{O}$ (strains: $\mathrm{O}$
Manisa + O 3039), A (strain: A Iran 05) and SAT-2 (strains: ERI + ZIM). Large ruminants (LR) were vaccinated against $\mathrm{O}$, A and SAT-2, whereas small ruminants (SR) were vaccinated only against $\mathrm{O}$ and $\mathrm{A}$. In order to gain a better understanding of the epidemiological situation in the country, a cooperation agreement was signed (in 2012) between the Libyan Ministry of Agriculture represented by the Libyan National Center of Animal Health $(\mathrm{NCAH})$, and the Italian Government represented by Ministry of Health. Specific activities were designed and conducted in collaboration with the Istituto Zooprofilattico Sperimentale della Lombardia e dell'Emilia Romagna (IZSLER) in Brescia, Italy, an OIE/FAO FMD reference laboratory. A surveillance system was designed by Libyan, FAO, EuFMD and IZSLER experts, and was then implemented during the year 2013.

This project had a structure of three main components: (I) Collection of samples from clinically affected animals in FMD suspected outbreaks: samples 
(vesicular epithelium, swabs, blood) for virus isolation and identification have been collected from suspected cases during the second half of 2013 from different areas in the country; (II) Evaluation of the immune response of vaccinated animals by collecting blood samples at the point of initial vaccination (day 1) and 30 days post vaccination, and (III) Investigation of the level of FMD virus circulation by detection of nonstructural proteins (NSP) antibodies, and the serotypes present by detecting of structural proteins (SP) serotype-specific antibodies by the collection of sera samples from all over the country.

This study was focused mainly on the third of these components to measure the level of NSP antibodies as indicator of past or current FMDV infection, irrespective of the vaccination status. Subsequently SP antibodies were also tested to gather information on the circulating FMDV serotypes, furthermore, and for vaccinated animals, this will show the level of antibodies following vaccination. The wider aim of this work was to support surveillance activities that are required in order for the country to progress from PCPFMD stage 1 to stage 2. These studies complemented phylogenetic analysis of sequences recovered from FMD virus positive samples collected from Libya that indicated a strain belonging to O/ME-SA/Ind-2001 lineage, which is derived from the Indian subcontinent, was circulating in the country (Valdazo-González et al., 2014; Knowles et al., 2016).

\section{Materials and Methods}

\section{Study area}

Libyan NCAH is responsible for seven regional animal health branches (Green Mountain, Benghazi, Middle Area, Zawiyah, Tripoli, West Mountain and Sabha). These animal health branches provide public veterinary services to cover the whole country. This study exploited samples from many Libyan cities that were collected by the National Veterinary Services.

\section{Sampling strategy and study design}

FMD susceptible animals in Libya are mainly cattle, sheep and goats. The LR (cattle) population in the country is around 150,000 and 6,500,000 for SR (sheep and goats). The sampling scheme varied according to the species. For each randomly selected owner, a questionnaire was completed by the veterinarian in order to get some basic information about the owner, the farm, collected samples and some risk factors.

For LR, a random selection of owners from different regions of the country was carried out. From each of the randomly selected farms, a maximum of 10 individual blood samples (the preferred age was 6-18 months) from the herd (all cows were sampled if the total number of animals was less than 10) were collected from two age categories: (I) 6-12 months of age and (II) over than 12 months of age. For SR, a two stage sampling design was carried out in order to randomly select owners from all over the country who have at least 100 heads per herd. From each herd a total number of 48 samples were collected from three age categories: (I) 16 samples from the 6 months to less than 12 months age; (II) 16 from animals between 12 and 24 months of age and (III) 16 from animals that were more than 24 months of age.

\section{Study animals and sample size}

A total number of 4,221 serum samples were collected during the year 2013 from LR and SR in Libya. For LR, a total number of 1428 serum samples were collected from 357 farms from 29 cities. Whereas for SR, a total number of 2,793 serum samples were collected from 141 farms from 39 cities.

\section{Serological testing}

The samples were analysed in Brescia, Italy, at IZSLER, an OIE/FAO FMD reference laboratory. Different tests, developed at IZSLER, were used: (i) a NSP-ELISA (3ABC-ELISA) for the detection of antibodies against NSP; these are elicited after an infection and are common to all FMDV serotypes; (ii) a series of three competitive ELISAs for the detection and serotyping of antibodies to the SP of FMDV serotypes O, A and SAT-2, in order to indirectly identify the viral serotypes circulating in Libya.

\section{NSP-ELISA}

The serological assay used to detect anti-NSP antibodies was the previously validated $3 \mathrm{ABC}$-trapping ELISA, (Brocchi et al., 2006), in the format of readyto-use kit, with pre-sensitized ELISA immuno-plates, peroxidase-conjugated anti-ruminant $\mathrm{IgG}$, control sera and TMB chromogen, produced at IZSLER, Brescia, Italy.

According to a previous validation study, the diagnostic performance of the IZSLER-Brescia kit are comparable to those of the OIE index test (Panaftosa-screening ELISA) described in the Diagnostic Manual of the World Organization for Animal Health. In particular, the specificity exceeds $99 \%$ and the sensitivity varies depending on the time elapsed after infection and on the previous vaccination status, achieving $100 \%$ for nonvaccinated cattle exposed to infection and $86.4 \%$ for the detection of carriers in vaccinated cattle (Brocchi et al., 2006).

\section{Monoclonal antibody (MAb)-based Solid Phase} Competitive ELISA (SPCE)

Ready-to-use kits developed and produced by IZSLER have been used for detection and titration of antibodies against FMDV serotypes O, A and SAT-2 (Brocchi et al., 2012; Dho et al., 2014).

The common principle of each assay corresponds to a solid phase competitive ELISA (SPCE) based on a peroxidase-conjugated, neutralizing monoclonal antibody (MAb), specific for a FMDV serotype. In the ready-to-use kit, ELISA microplates are supplied precoated with inactivated FMDV antigens captured by 
homologous serotype-specific MAbs. Appropriately diluted sera are incubated with the trapped antigen, enabling the specific antibodies present in the sample to bind to the antigen. Then, the anti-FMDV serotypespecific MAb, conjugated with peroxidase, is dispensed: its reaction with the homologous antigen will be inhibited by antibodies of positive sera previously bound to the virus, while in case of negative sera the conjugated MAb can bind to the FMDV antigen. After incubation, the unbound conjugate is removed by washing and the TMB substrate/chromogen solution is delivered into wells. A colorimetric reaction develops if the conjugated $\mathrm{MAb}$ has bound to the virus, i.e. if test serum is negative, while colour development is inhibited by positive sera. Antigen and conjugate concentrations are precalibrated in order to give a suitable reaction value (OD). After addition of a stop solution, the optical density of the developed color is read by a microplate photometer. Serum samples can be screened at a single dilution 1/10, to obtain a simple qualitative (positive/negative) result; in the present study all sera were titrated by analyzing serial dilutions and the endpoint titre was calculated as the highest dilution inhibiting $50 \%$ reaction. The test can be applied to measure antibodies in serum or plasma samples of FMDV infected or vaccinated animals of any susceptible species. Since antibodies cross-reactive among different serotypes may be elicited and are detectable by ELISA assays, type-specificity cannot be perfect. However, significant differences in titres against different serotypes may help in interpretation.

\section{Data analysis:}

The data collected was entered into Microsoft Excel spreadsheet and coded for analysis. The seroprevalence for FMD NSP antibodies was standardized by using the following formula:

Direct adjusted sero-prevalence $=\sum$ Sero-prevalence \% (SP) X Reference population distribution (RPD) over all age group strata (Fleiss, 1973).

The NSP sero-prevalence in each age-group was estimated as $p=\frac{N S P+}{n}$

Where $n$ is the total number of animals counted in the specific age-group considered. Whereas if at least one positive NSP animal was found in a one farm or a city, then this farm or city was considered as FMD positive. For each age-group; the age related risks of infection were estimated through the following equation (Vynnycky and White, 2010):

$$
R_{t}=1-\frac{S_{t}}{S_{t-1}}
$$

Where: $S_{t}$ is the proportion of susceptible in the generic $t$ age-group and $S_{t-1}$ is the proportion of susceptible in the preceding age-group. The age-specific monthly incidence rate $m_{t}$ (monthly force of infection) was calculated according to the following:

$$
m_{t}=\frac{-\ln \left(1-R_{t}\right)}{a_{t}-a_{t-1}}
$$

Where: The average age $a_{t}$ of the SR in each age-group as well as the difference $\left(a_{t}-a_{t-1}\right)$ between two adjacent age-groups were estimated. Pearson's chi-square tests were used to detect significant differences in seropositivity among and between age groups. Epidemiologic data (location and serotypes) were mapped. In all the analysis, the confidence level was set at $95 \%$ and $p<0.05$ set for significance. The Correlation between number of animals and the sero-prevalence of FMD at city level was calculated using Pearson Correlation.

\section{Results}

Using the NSP ELISA test, the sero-prevalence estimated in LR and SR was $19.0 \%$ (271/1428) with 95\% CI (16.9-21.0) and 13.5\% (378/2793) with 95\% CI (12.3-14.8) respectively (Table 1). The age standardized sero-prevalence of FMD in the two species was 18.3 with $95 \%$ CI (2.4-34.3) and 15.5 with 95\% CI (4.1-26.9) for LR and SR respectively (Table 2).

The distribution FMD sero-prevalence in $\mathrm{NCAH}$ branches:

The standardized sero-prevalence was calculated for the seven NCAH branches. For SR: the highest seroprevalence was in Benghazi (25.8\%) and Tripoli (22.1\%) branches followed by West Mountain (13.2\%), Middle Area (12.3\%), Green Mountain (9.3\%) and Sabha $(7.7 \%)$ and the last Zawiyah (0.9\%) (Fig. 1 and Table 3).

For LR: the highest sero-prevalence was in Green Mountain (28.4\%) and Benghazi $(23.2 \%)$ branches followed by Zawiyah (15.4\%), Sabha (15.1\%), Tripoli $(14.8 \%)$ and West Mountain (6.8\%) and last was in Middle Area (5.7\%) (Fig. 2 and Table 3).

The age distribution of sero-prevalence of FMD:

There were significant differences in the seroprevalence estimated among the age groups in $\mathrm{SR}\left(\mathrm{X}^{2}=\right.$ 118.1, $\mathrm{P}=0.000)$.

The sero-prevalence of FMD in SR was 3.7, 13.6 and 21.3 for age groups $<1$ year, $1-2$ year and $>2$ year respectively. The prevalence risk ratio was 3.3 with $95 \% \mathrm{CI}(2.3$ - 4.9) and 5.7 with $95 \% \mathrm{CI}(4.0$ - 8.3) for age group $1-2$ year and $>2$ year respectively comparing to $<1$ year (Table 4 ).

Also in LR, there were significant differences in the sero-prevalence estimated among the age groups $\left(\mathrm{X}^{2}=\right.$ 4.95, $\mathrm{P}=0.026$ ). The sero-prevalence of FMD was 12.3 and 19.8 for age groups $<1$ year and $\geq 1$ year respectively with risk ratio 1.6 with $95 \%$ CI (1.04 - 2.5) as shown in Table 4. 
Table 1. The sero-prevalence of FMD in Libya determined using NSP ELISA.

\begin{tabular}{lcccccc}
\hline Species & $\begin{array}{c}\text { No. of } \\
\text { samples }\end{array}$ & $\begin{array}{c}\text { No. of positive } \\
\text { samples }(\%)\end{array}$ & $\begin{array}{c}\text { No. of } \\
\text { farms }\end{array}$ & $\begin{array}{c}\text { No. of positive } \\
\text { farms }(\%)\end{array}$ & $\begin{array}{c}\text { No. of } \\
\text { cities }\end{array}$ & $\begin{array}{c}\text { No. of positive } \\
\text { cities }(\%)\end{array}$ \\
\hline LR & 1,428 & $271(19 \%)$ & 357 & $134(37.5 \%)$ & 29 & $20(68.9 \%)$ \\
SR & 2,793 & $378(13.5 \%)$ & 141 & $76(53.9 \%)$ & 39 & $30(76.9 \%)$ \\
Total & 4,221 & $649(15.4 \%)$ & 498 & $210(42.9 \%)$ & 44 & $43(97.7 \%)$ \\
\hline
\end{tabular}

Table 2. The standardized sero-prevalence of FMD in Libya.

\begin{tabular}{lccccc}
\hline Species & $\begin{array}{c}\text { Age group } \\
\text { (months) }\end{array}$ & $\begin{array}{c}\text { Sero-prevalence } \% \\
(\text { SP) }\end{array}$ & $\begin{array}{c}\text { Reference population } \\
\text { distribution (RPD) }\end{array}$ & $\begin{array}{c}\text { Product } \\
\text { (SP*RPD) }\end{array}$ & $\begin{array}{c}\text { Standardized SP } \\
\sum \text { SP*RPD }\end{array}$ \\
\hline \multirow{2}{*}{ LR } & $6-<12$ & 12.3 & 0.2 & 2.46 & 18.3 \\
& $\geq 12$ & 19.8 & 0.8 & 15.84 & $(95 \%$ CI 2.4-34.3) \\
SR & $6-<12$ & 3.7 & 0.2 & 0.74 & 15.5 \\
& $12-24$ & 13.6 & 0.3 & 4.08 & $(95 \%$ CI $4.1-26.9)$ \\
\hline
\end{tabular}

Table 3. The standardized sero-prevalence of FMD in LR and SR by branch.

\begin{tabular}{lcccccccc}
\hline \multirow{2}{*}{ Branch } & \multicolumn{2}{c}{ No. of Farms } & \multicolumn{2}{c}{ No. of infected farms $(\%)$} & \multicolumn{2}{c}{ No. of Samples } & \multicolumn{2}{c}{ Sero-prevalence $(\%)$} \\
\cline { 2 - 9 } & LR & SR & LR & SR & LR & SR & LR & SR \\
\hline Green Mountain & 133 & 25 & $57(42.9)$ & $12(48.0)$ & 368 & 572 & 28.4 & 9.3 \\
Benghazi & 18 & 35 & $7(38.9)$ & $22(62.9)$ & 106 & 834 & 23.2 & 25.8 \\
Middle Area & 7 & 19 & $2(28.6)$ & $5(26.3)$ & 42 & 87 & 5.7 & 12.3 \\
Zawiyaha & 72 & 8 & $20(27.8)$ & $1(12.5)$ & 227 & 182 & 15.4 & 0.9 \\
Tripoli & 88 & 15 & $38(43.2)$ & $12(80.0)$ & 516 & 282 & 14.8 & 22.1 \\
West Mountain & 33 & 20 & $6(18.2)$ & $16(80.0)$ & 132 & 610 & 6.8 & 13.2 \\
Sabha & 6 & 19 & $4(66.7)$ & $8(42.1)$ & 37 & 226 & 15.1 & 7.7 \\
Total & 357 & 141 & $134(37.5)$ & $76(53.9)$ & 1428 & 2793 & 18.3 & 15.5 \\
\hline
\end{tabular}

Table 4. Estimated prevalence risk of FMD in SR and LR by age group.

\begin{tabular}{|c|c|c|c|c|c|c|}
\hline Age group & No. of Samples & $\begin{array}{c}\text { No. of positive } \\
\text { samples (\%) }\end{array}$ & $\begin{array}{c}95 \% \text { CI } \\
\text { Lower-Upper }\end{array}$ & $X^{2}$ & P-Value & $\begin{array}{c}\text { RR } \\
(95 \% \mathrm{CI})\end{array}$ \\
\hline SR & & & & 118.1 & 0.000 & \\
\hline$<1$ year* & 804 & $30(3.7)$ & $2.5-5.3$ & & & \\
\hline $1-2$ years & 980 & $133(13.6)$ & $11.5-15.9$ & & & $3.3(2.3-4.9)$ \\
\hline$>2$ years & 1009 & $215(21.3)$ & $18.8-24.0$ & & & $5.7(4.0-8.3)$ \\
\hline LR & & & & 4.95 & 0.026 & \\
\hline$<1$ year* & 154 & $19(12.3)$ & $7.6-18.6$ & & & \\
\hline$\geq 1$ year & 1274 & $252(19.8)$ & $17.6-22.1$ & & & $1.6(1.04-2.5)$ \\
\hline
\end{tabular}

Table 5. Estimated monthly incidence rate per 1000 animals for FMD in SR for each age group.

\begin{tabular}{cccccc}
\hline $\begin{array}{c}\text { Age-group } \\
\text { (in months) }\end{array}$ & Prevalence (p) & $\begin{array}{c}\text { Average age } a_{t} \\
\text { (in months) }\end{array}$ & $\begin{array}{c}\text { Proportion of } \\
\text { susceptible } \mathrm{S}_{\mathrm{t}}=(1-\mathrm{p})\end{array}$ & $\begin{array}{c}\text { Age related } \\
\text { risks } \\
{\left[1-\left(\mathrm{S}_{\mathrm{t}} / \mathrm{S}_{\mathrm{t}-1}\right)\right]}\end{array}$ & $\begin{array}{c}\text { Age-specific monthly } \\
\text { incidence rate/1000 animals } \\
m_{t}=-\ln \left(1-R_{t}\right) /\left(a_{t}-a_{t-1}\right)\end{array}$ \\
\hline $6-<12$ & 0.037 & 8.86 & 0.963 & 0.037 & 4.2 \\
$12-24$ & 0.136 & 19.84 & 0.864 & 0.103 & 9.9 \\
$>24$ & 0.213 & 47.9 & 0.787 & 0.089 & 3.3 \\
\hline
\end{tabular}

*Age related risks are estimated over different lengths of times within the different age-groups. 


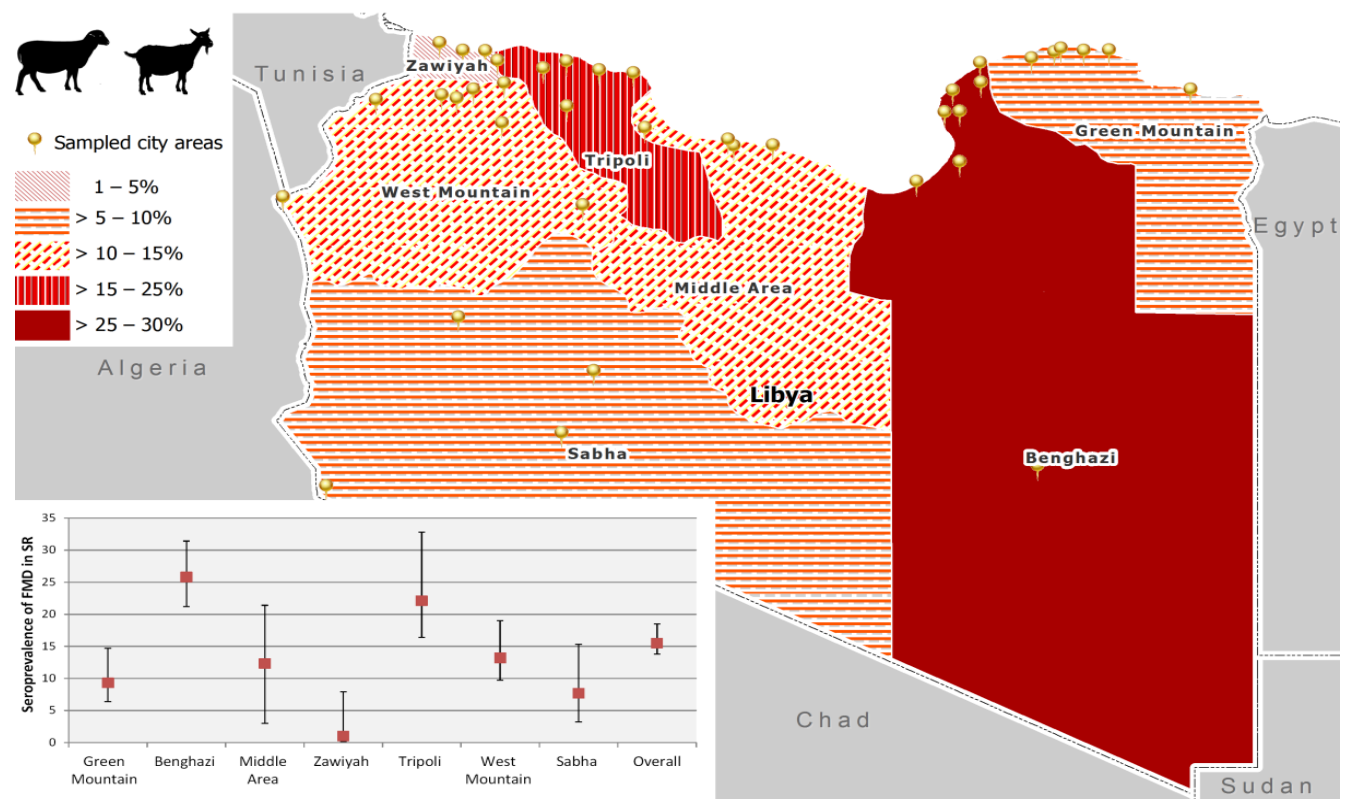

Fig. 1. Estimated sero-prevalence of FMD in SR by branch.

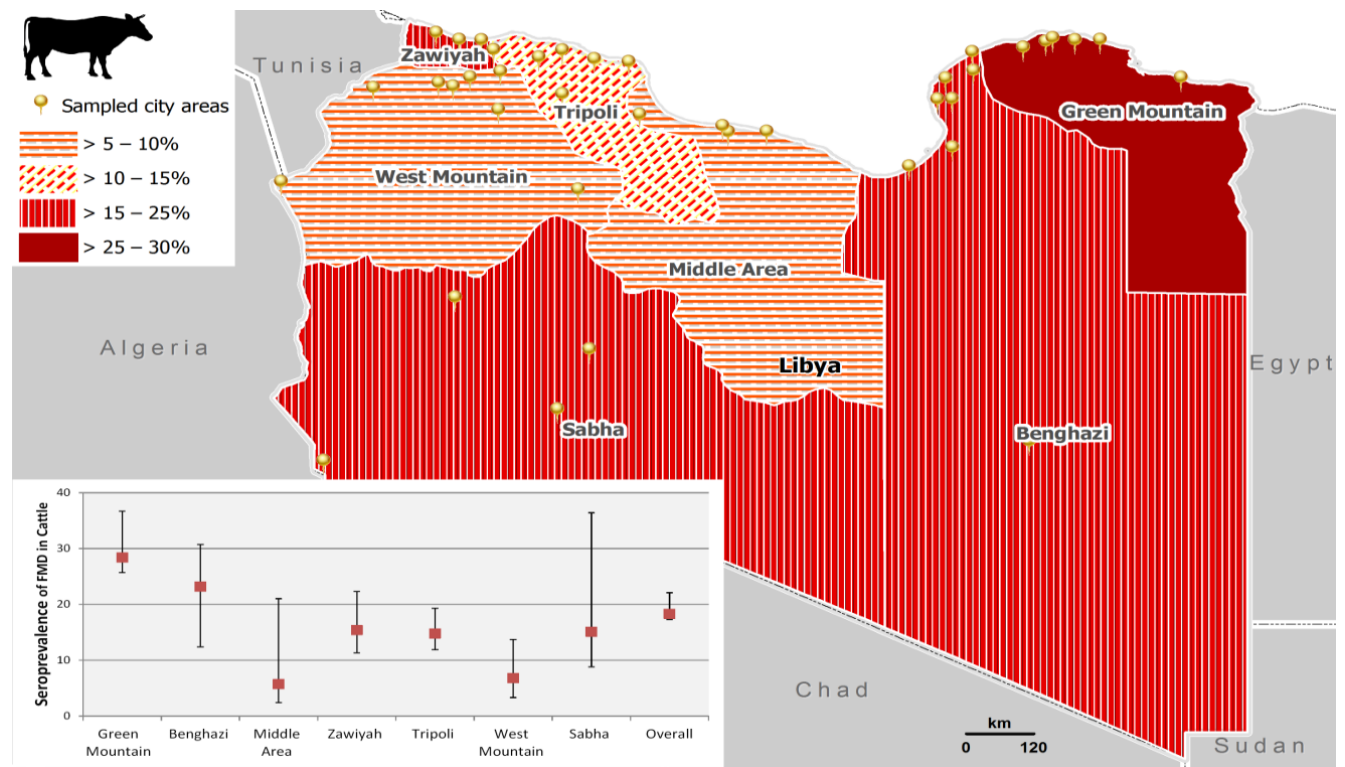

Fig. 2. Estimated Sero-prevalence of FMD in LR by branch.

The estimated monthly incidence rate was 4.2 per 1,000 animals between 0 and 8.9 months of age that increased up to 9.9 per 1,000 animals between 8.9 and 19.8 months and then dropped to 3.3 per 1,000 animals once the animals reached an average age of 47.9 months (Table 5).

\section{Circulating FMD serotypes:}

All NSP positive samples were subjected to SP ELISA for O, A and SAT-2 serotypes. The majority of the SR positive samples were serotype $\mathrm{O}(65.9 \%)$, then $\mathrm{A}$ $(25.7 \%)$ and only $0.3 \%$ for SAT-2. The serotype O varied within the branches from $0-81.6 \%$ whereas serotype A ranged from 12.3 to 100 . In LR: the mean level of serotype $\mathrm{O}$ among NSP positive samples was $45.9 \%$ which ranged within the branches from $14.3-$ $100 \%$, whereas the mean level of serotype A was $41.7 \%$ ranging from $0-67.8 \%$, while serotype SAT-2 was lower at $0.8 \%$.

The overall percentage of $\mathrm{O}$ serotype in less than oneyear age group for both SR and LR was almost two times higher than A serotype. The percentage of $\mathrm{O}$ serotype was higher in Green Mountain, Benghazi, Zawiyah and West Mountain whereas the percentage A serotype was higher in Middle Area, and Sabha Branch 
for SR (Table 6; Fig. 3 and 4). There was moderate correlation between the sero-prevalence of FMD in LR and the number of SR (Pearson Correlation value, 0.632 with p-value 0.000 ), low correlation between the sero-prevalence of FMD in cattle and the number of LR (Pearson Correlation value, 0.386 with p-value 0.042) and low correlation between the number of SR and cattle (Pearson Correlation value, 0.479 with $\mathrm{p}$-value 0.002 ) as shown in Table 7.

\section{Discussion}

A surveillance study for FMD is an essential requirement before practical attempts are made to control the disease. For instance, in a vast country like Libya, with an area approaching $1,760,000 \mathrm{~km}^{2}$, and six neighbouring countries where four FMDV serotypes (O, A, SAT-1, and SAT-2) are known to prevail (records), besides illegal animal movement along most of the borders, the task of FMD control is challenging.

Table 6. The distribution and the percentage of FMD serotypes of positive samples collected from SR and LR for age group less than one year.

\begin{tabular}{|c|c|c|c|c|c|c|}
\hline \multirow[b]{2}{*}{ Branches } & \multirow[b]{2}{*}{ Species } & \multirow{2}{*}{$\begin{array}{l}\text { No. of Positive } \\
\text { Samples }\end{array}$} & \multicolumn{4}{|c|}{ Serotype No. $(\%)$} \\
\hline & & & $\mathrm{O}$ & A & $\mathrm{O}, \mathrm{A}$ & $\begin{array}{c}\text { No } \\
\text { serotype }\end{array}$ \\
\hline \multirow{2}{*}{ Green Mountain } & SR & 2 & $2(100)$ & & & \\
\hline & LR & 6 & $3(50.0)$ & $3(50.0)$ & & \\
\hline \multirow{2}{*}{ Benghazi } & SR & 15 & $12(80.0)$ & $2(13.3)$ & $1(6.7)$ & \\
\hline & LR & 0 & & & & \\
\hline \multirow{2}{*}{ Middle Area } & SR & 1 & & $1(100)$ & & \\
\hline & LR & 0 & & & & \\
\hline \multirow{2}{*}{ Zawiyah } & SR & 0 & & & & \\
\hline & LR & 2 & $2(100.0)$ & & & \\
\hline \multirow{2}{*}{ Tripoli } & $\mathrm{SR}$ & 3 & $1(33.3)$ & $2(66.7)$ & & \\
\hline & LR & 10 & $5(50.0)$ & $2(20.0)$ & $3(30.0)$ & \\
\hline \multirow{2}{*}{ West Mountain } & SR & 6 & $3(50.0)$ & $2(33.3)$ & & $1(16.7)$ \\
\hline & LR & 1 & & $1(100.0)$ & & \\
\hline \multirow{2}{*}{ Sabha } & SR & 3 & $1(33.3)$ & $2(66.7)$ & & \\
\hline & LR & 0 & & & & \\
\hline \multirow{2}{*}{ Over All } & SR & 30 & $19(63.3)$ & $9(30.0)$ & $1(3.3)$ & $1(3.3)$ \\
\hline & LR & 19 & $10(52.6)$ & $6(31.6)$ & $3(15.8)$ & \\
\hline
\end{tabular}

Table 7: The correlation between the sero-prevalence of FMD and the number of SR and LR in 40 cities.

\begin{tabular}{|c|c|c|c|c|}
\hline & & $\%$ of FMD in SR & \# of the LR & \# of the SR \\
\hline \multirow{3}{*}{$\%$ of FMD in LR } & Pearson Correlation & .171 & $.386^{*}$ & $.632^{* *}$ \\
\hline & P-Value & .437 & .042 & .000 \\
\hline & $\mathrm{N}$ & 23 & 28 & 28 \\
\hline \multirow{3}{*}{$\%$ of FMD in SR } & Pearson Correlation & 1 & -.020 & -.043 \\
\hline & P-Value & & .911 & .803 \\
\hline & $\mathrm{N}$ & & 35 & 36 \\
\hline \multirow{3}{*}{ \# of the LR } & Pearson Correlation & & 1 & $.479^{* *}$ \\
\hline & P-Value & & & .002 \\
\hline & $\mathrm{N}$ & & & 40 \\
\hline
\end{tabular}



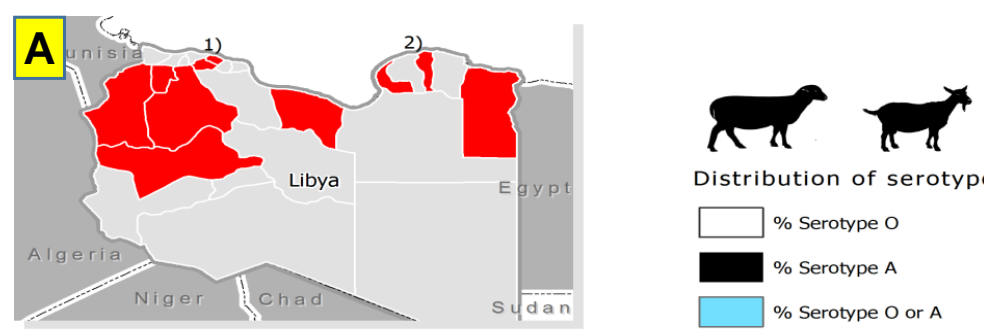

Distribution of serotypes (less than 1 year)
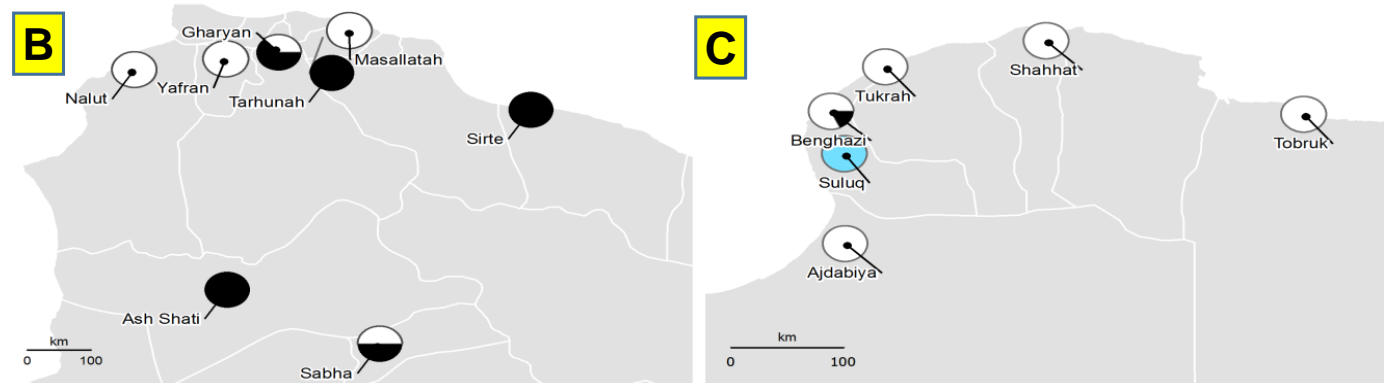

Fig. 3. Distribution of FMD serotypes in age group less than 1 year in SR as indication of recent FMD infections. (A): In the whole country. (B): In cities of the western part of the country. (C): In cities of the eastern part of the country.
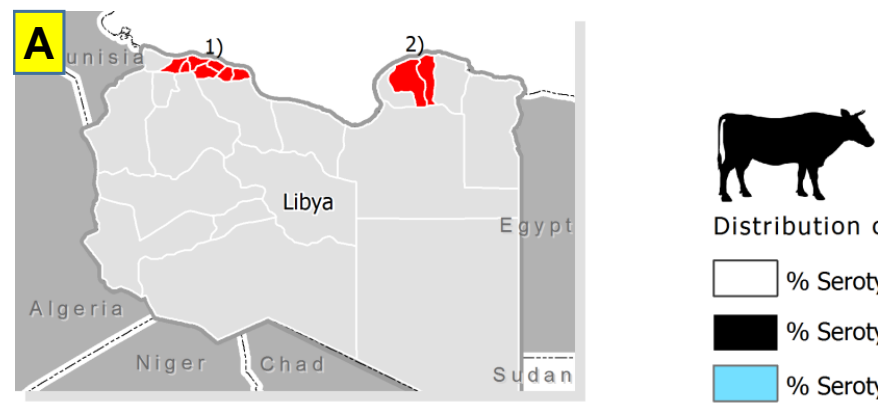

Distribution of serotypes (less than 1 year)

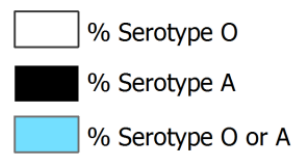

B

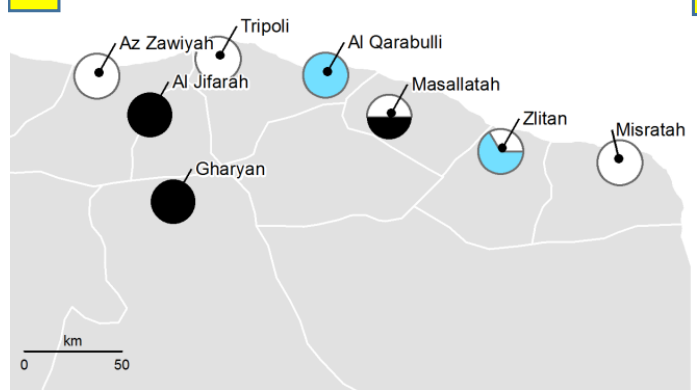

C

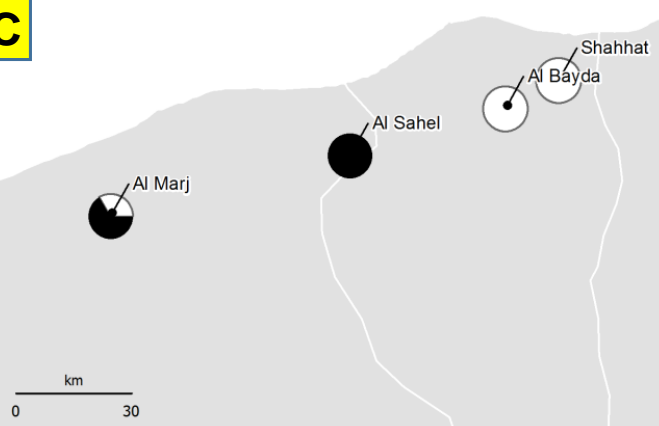

Fig. 4. Distribution of FMD serotypes in age group less than 1 year in LR as indication of recent FMD infections. (A): In the whole country. (B): In cities of the western part of the country. (C): In cities of the eastern part of the country.

The precise routes by which the new FMDV strain O/ME-SA/Ind-2001 was introduced into Libya in 2013 are not yet fully understood. This same virus strain has spread beyond Libya to Tunisia in April 2014 (WRLFMD, 2014a), then to Algeria in July 2014 (WRLFMD, 2014b) and more recently to Morocco in October 2015 (Bachanek-Bankowska et al., 2016). Our results suggest that FMD is endemic in Libya and the working hypothesis is that the virus is maintained mainly through the SR population. This hypothesis was supported by the profile of NSP antibodies in SR that showed a progressive increase in the sero-positivity concordant with the increasing average age of the animals tested with OR vary from 3.3 to 5.7 for age group 1-2 year and $>2$ years compared to $<1$ year age group, in contrast to LR where OR only 1.6 for $\geq 1$ year age group compared to $<1$ year of age group. An additional reason that may lead to consider SR as 
candidate reservoirs of FMD virus in Libya is their relatively high number $(6,500,000$ approximately) in comparison with the estimated total population of LR (approximately 150,000 heads) with a ratio SR/LR 44/1. Furthermore, the livestock movement and transhumance or nomadism practices of SR are common practice in Libya. Another relevant element identified through our study is that the correlation between number of animals and the sero-prevalence of FMD at city level was moderate between the seroprevalence of FMD in LR and the number of SR (Pearson Correlation value, 0.632 with p-value 0.000) and low correlation between the sero-prevalence of FMD in cattle and the number of LR (Pearson Correlation value, 0.386 with p-value 0.042 ).

Such a combination of factors could determine that the clinical disease in SR (already difficult to be recognized) may go undetected, also because of the relatively low number of cases occurring in the overall population, the disease may then be clearly seen only once it spillovers in LR where the clinical signs are more apparent. For the above-mentioned reasons, sheep might act as a source of infection for cattle. Therefore, sheep vaccination would be an effective way to limit the spread of FMD outbreaks.

In general, vaccination against FMD in LR, and sometimes also in SR is the common strategy used in North Africa and Middle East in order to control the disease. Vaccines used in these countries were from a wide variety of sources, including producers based within the region, or from international vaccine producers.

FMD control in this region is not an easy task to be done due to the lack of relevant and harmonised surveillance programmes and the lack of transparency and collaboration between these countries. The long borders between countries in the region and the illegal animal movement between neighbouring countries make disease control even more difficult. Furthermore, some countries are not able to secure constant and continuous financial funding and budgets for FMD surveillance and control programmes.

Bravo de Rueda et al. (2015) developed a method to determine the (partial) reproduction ratios $(R)$ for mixed populations of cattle and sheep by using published experimental transmission data and evaluated different vaccination strategies, and concluded that "vaccination of cattle only in mixed population consisting of sheep and cattle will in most cases be sufficient for controlling FMDV epidemics". In Libya, one possible approach for the vaccination programme could be: (i) to protect LR against clinical disease with an extensive vaccination programme; (ii) to better characterise risk hotspots and transmission pathways among the SR population which should possibly lead to formulate a preventive program targeting the sub-populations where the risk of infection will be estimated to be higher. It will be extremely important, if such approach is adopted, to thoroughly review the definition of a suspected case among SR as the overall sensitivity for detecting FMD would significantly decrease if LR were vaccinated. During the first quarter of 2012, Libya had an epidemic of FMD all over the country (in average of 18 FMD infected herds per day; unpublished data). A mass vaccination was introduced in Libya by the end of 2012 to reduce the negative economic impact of FMD.

In our results, both for SR and LR, serotype $\mathrm{O}$ was the highest followed by serotype A. In Sudan, the main FMDV circulation in seven states in 2010 in cattle was A $(78.1 \%), \mathrm{O}(69.4 \%)$, SAT-2 $(44.0 \%)$ and SAT-1 $(20.2 \%)$ whereas in sheep was O $(27.5 \%)$, SAT-2 (9.1\%), A (8.7\%) and SAT-1 (5.1\%) (Habiela et al., 2010). Another study in Khartoum state Sudan by Noureldin and Elfadil (2014) found that serotype O $(82.6 \%)$ and SAT-2 (40\%) were the main circulating FMDVs in cattle. Raouf et al. (2012) in a study conducted in western Sudan showed positive results for SAT-2 (40\%) and O (25\%). In Egypt, serotype O (19.5\%) and A (14.9\%) were detected in sheep (Hassan et al., 2011).

In this study, a sero-positive rate of $18.3 \%$ with $95 \% \mathrm{CI}$ (2.4 - 34.3) was detected in cattle, which was similar to other studies conducted in Malaysia, Bangladesh and Somaliland (Hasaballa and Abbo, 2010; Sarker et al., 2011; Elnaker et al., 2012). These values are in contrast to the FMD sero-prevalence study conducted in the neighbouring country of Sudan where higher values of $79.2 \%$ (Habiela et al., 2010) and $25-56 \%$ in south of Sudan (Ochi et al., 2014) were detected.

It is not easy to compare the results for this study (Libya) with other studies due to the variety of different involving factors. Some examples of these factors would be: the differences in husbandry management, size of herd, total number of LR, presence of reservoirs (no buffaloes in Libya), the immunity status of cattle, the breed, the sampling design, the sensitivity and specificity of the diagnostic test, etc.

For LR, higher FMD sero-prevalence in the eastern part of the country might be associated with the transhumance and nomadism practices compared to other branches. Whereas, the lower sero-prevalence of FMD was in the Middle Area and West Mountain branches, that might be due to the small number of LR population in these areas.

The sero-prevalence in cattle revealed increasing of positive cases as the age increases (higher in older animals). This finding was similar to results obtained in other studies (Kahn et al., 2002; Gelaye et al., 2009; Sarker et al., 2011; Ochi et al., 2014). One explanation for that is that young cattle are always kept in pen and closed areas with less exposure and contact with other 
animals. Another study by Kahn et al. (2002), noticed that adult cattle that kept for long time with history of previous infection act as chronic carriers. The high prevalence in old age group is likely due to constant reexposure to FMD and indicates the cumulative experience of the population with the agent (Murphy et al., 1999). However, few other studies showed higher FMD sero-prevalence in calves than adult cattle (Perry et al., 2003; Rufael et al., 2008).

The standardized FMD sero-prevalence of $15.5 \%$ with 95\% CI (4.1-26.9) was obtained for SR livestock. These results were almost similar to those reported in Egypt (18.4\%) by Hassan et al. (2011) where higher prevalence was reported in males (29\%) than females (13\%). In India, 20.4\% sheep and $13.6 \%$ goats were found to be FMD NSP positive (Rout et al., 2014). Higher sero-prevalence was reported in Sudan (24.3\%) (Habiela et al., 2010). In another study conducted in India showed that the overall sero-prevalence was 38\% in goats (Ranabijuli et al., 2010).

For SR, the sero-prevalence varied between different Libyan NCAH branches. The highest FMD seroprevalence reported in Benghazi and Tripoli branches (Tripoli and Benghazi are the two main cities of Libya with about $2 / 3$ of the total Libyan inhabitants), might be associated with the herd management and movement of animals towards the two big cities as well as these two cities have large number of livestock markets.

The present study revealed that there was statistical association between age of SR animals and seropositive rate for FMD $(\mathrm{P}<0001)$. In another study in South Sudan, Ochi et al. (2014) found that the FMDsero-prevalence in sheep < one-year-old was $12.5 \%$ and $31 \%$ in age group $>3$ year.

The age-related risks of infection for FMD in SR were estimated for the three age groups to evaluate the effect of the FMD vaccination that was applied during last quarter of the year 2012. Animals at age < one-year-old were not exposed to 2012 FMD outbreaks, therefore, these animals were expected to provide information about recent infections, whereas the older animals may have experienced the extensive 2012 FMD outbreaks. Before FMD outbreaks (the effect of years before 2012), the estimated monthly incidence rate per 1000 animals for FMD was 3.3 cases. During the year of the FMD outbreak (2012) the monthly incidence rate increased dramatically to 9.9 per 1000 animals. Following the vaccination, the monthly incidence rate decreased to 4.2 per 1000 animals. The results of the monthly incidence rate can be counted as an indicator and an indirect measurement for the efficacy and the success of the mass vaccination campaign.

In conclusion, the present study indicates that FMD has been circulating in large areas of Libya and the majority of the outbreaks were undetected because of inadequate national disease surveillance systems. The NSP serologic profile observed in both small and large ruminants supports the hypothesis of an endemic level of FMDV. While in 2013, serotype O (O/ME-SA/Ind2001 lineage) was the only serotype isolated from clinical samples, a deeper evaluation of SP antibodies titers cannot rule out the concurrent presence of serotype A.

Further research should be conducted to get better understanding of the livestock production, data collection on the management system and risk factors analysis. Therefore, findings provide insight information on the epidemiology of FMD, scientifically sound strategies could be developed for disease control to limit the effect of FMD on Libyan animal livestock.

\section{Acknowledgments}

Authors are grateful to the staff of the Libyan National Center for Animal Health (NCAH) especially to those who contributed in collecting samples and filling questionnaires. Special thanks to Zohra Bensouliman, Khalid Aswaise, Saad Altayef and Ali Milad from NCAH who helped in organizing samples in Tripoli and helping by testing samples in IZSLER lab in Brescia. Authors are grateful to Giulia Conchedda and Giuseppina Cinardi from AGAL, FAO, Rome, for helping in preparing the maps. The authors would like to express their gratitude to the staff of the National Reference Centre for Vesicular Diseases, Biotechnology Department, OIE/FAO reference laboratories for FMD and for SVD, IZSLER, in Brescia, Italy, and also to the Italian Ministry of Health for providing the financial support for testing all samples in IZSLER lab.

\section{Conflict of interest:}

The author declares that there is no conflict of interest.

\section{References}

Bachanek-Bankowska, K., Wadsworth, J., Gray, A., Abouchoaib, N., King, D.P. and Knowles, N.J. 2016. Genome sequence of foot-and-mouth disease virus serotype $\mathrm{O}$ isolated from Morocco in 2015. Genome Announc. 4(2), e01746-15. doi:10.1128/genomeA.01746-15.

Bravo de Rueda, C., Dekker, A., Eble, P.L. and De Jong, M.C. 2015. Vaccination of Cattle Only is Sufficient to Stop FMDV Transmission in Mixed Populations of Sheep and Cattle. Epidemiol. Infect. 143(11), 2279-2286.

Brocchi, E., Bergman, I., Dekker, A., Paton, D., Sammin, D., Greiner, M., Grazioli, S., De Simone, F., Yadin, H., Haas, B., Bulut, N., Malirat, V., Neitzert, E., Goris, N., Parida, S., Sørensen, K. and De Clercq, K., 2006. Comparative evaluation of six ELISAs for the detection of antibodies to the nonstructural proteins of foot-and-mouth disease. Vaccine 24(47-48), 6966-6979. 
Brocchi, E., Spagnoli, E., Li, Y., Haas, B., De Clercq, K., Dho, G., Grazioli, S. and De Simone, F. 2012. Ready-to-use kits for detection of antibodies to FMDV serotypes O, A, Asia 1. Open Session of the standing technical and research committees of the EuFMD commission - Jerez de la Frontera, Spain, 29-31 October 2012.

Dho, G., Grazioli, S., Bugnetti, M., Pezzoni, G., Maree, F.F., Esterhuysen, J., Chitray, M., Scott, K. and Brocchi, E. 2014. "Ready-to-use kits for the detection of antibody to FMDV serotypes SAT1 and SAT2". Open Session of the Standing Technical and research Committees of EuFMD, Cavtat (Croatia), 29-31 October 2014, pp: 140141.

Elnaker, Y.F., Sayed-Ahmed, M., El-Beskawy, M., ElSawalhy, A.A. and Wabacha, J.K. 2012. Seroprevalence of FMD in cattle, sheep and goats in Somaliland. Bull. Anim. Health Prod. Africa 60(4), 383-392.

FAO-OIE. 2012. The Progressive Control Pathway for FMD control (PCP-FMD): Principles, Stage Descriptions and Standards. 2012. http://www.fao.org/fileadmin/user_upload/eufmd/d ocs/PCP/PCP_Guidelines_Eng_2012web.pdf.

Fleiss, J.L. 1973. Statistical method for rates and proportions. Torinto, Canada: John Wiley \& Sons, pp: 155-164.

Gelaye, E., Ayelet, G., Abere, T. and Asmare, K. 2009. Seroprevalence of foot and mouth disease in Bench Maji zone, Southwestern Ethiopia. J. Vet. Med. Anim. Health 1(1), 5-10.

Habiela, M.M., Alamin, A.G., Raouf, Y.A. and Ali, Y.H. 2010. Epizootiological study of foot and mouth disease in the Sudan: the situation after two decades. Vet. Archiv. 80(1), 11-26.

Hasaballa, H. and Abbo, A. 2010. Prevalence of Foot and Mouth Disease and Evaluation of Effectiveness of Vaccination in Malaysian Cattle. Master thesis, Universiti Putra Malaysia.

Hassan, A.I., Ebeid, M.H., Hamoda, F.K. and Azab, A.M.H. 2011. Studies on Foot and Mouth Disease Virus type O1, A in Sheep. PhD thesis, Benha University, Egypt.

Kahn, S., Geale, D.W., Kitching, P.R., Bouffard, A., Allard, D.G. and Duncan, J.R. 2002. Vaccination against foot-and-mouth disease: the implications for Canada. Can. Vet. J. 43(5), 349-354.

Knowles, N.J., Bachanek-Bankowska, K., Wadsworth, J., Mioulet, V., Valdazo-González, B., Eldaghayes, I.M., Dayhum, A.S., Kammon, A.M., Sharif, M.A., Waight, S., Shamia, A.M., Tenzin, S., Wernery, U., Grazioli, S., Brocchi, E., Subramaniam, S., Pattnaik, B. and King, D.P. 2016. Outbreaks of Foot-and-Mouth Disease in Libya and Saudi Arabia During 2013 Due to an Exotic O/ME-SA/Ind-2001
Lineage Virus. Transbound. Emerg. Dis. 63(5), e431-435.

Murphy, A.F., Gibbs, J.E., Horzinec, C.M. and Studdert, J.M. 1999. Foot and Mouth Disease. In: Veterinary Virology. $3^{\text {rd }}$ edition California, Acadamic press USA, pp: 512-537.

Noureldin, A.M.M.A. and Elfadil, A.A.M. 2014. Prevalence and Risk Factors of Foot and Mouth Disease of Cattle in Khartoum State - Sudan. Master thesis, Sudan University of Science and Technology.

Ochi, E.B., Suliman, M.A. and Ismail, A.O. 2014. A Review on Epidemiology of Foot and Mouth Disease (FMD) in South Sudan. Report Opinion 6(11), 13-16.

OIE. 2012. "OIE Manual of Diagnostics for Foot and Mouth Disease: chapter 2.1.5," http://www.oie.int/fileadmin/Home/eng/Health_sta ndards/tahm/2.01.05_FMD.pdf.

Perry, B.D., Randolph, T.F., Ashley, S., Chimedza, R., Forman, T., Morrison, J., Poulton, C., Sibanda, L., Stevens, C., Tebele, N. and Yngstrom, I. 2003. The Impact and Poverty Reduction Implications of Foot and Mouth Disease Control in South Africa with Special Reference to Zimbabwe. Proceedings of the $10^{\text {th }}$ International Symposium on Veterinary Epidemiology and Economics, Available at: www.sciquest.org.nz.

Ranabijuli, S., Mohapatra, J.K., Pandey, L.K., Rout, M., Sanyal, A., Dash, B.B., Sarangi, L.N., Panda, H.K. and Pattnaik, B. 2010. Serological Evidence of Foot-and-Mouth Disease Virus Infection in Randomly Surveyed Goat Population of Orissa, India. Transbound. Emerg. Dis. 57(6), 448-454.

Raouf, Y.A., Tamador, M.A.A., Nahid, A.I. and Shaza, M. 2012. A survey for antibodies against current infection of foot-and-mouth disease virus in Sudanese cattle, sheep and goats using neutralization test. Bull. Anim. Health Prod. Africa 60(3), 351-358.

Rout, M., Senapati, M.R., Mohapatra, J.K., Dash, B.B., Sanyal, A. and Pattnaik, B. 2014. Serosurveillance of foot-and-mouth disease in sheep and goat population of India. Prev. Vet. Med. 113, 273-277.

Rufael, T., Catley, A., Bogale, A., Sahle, M. and Shiferaw, Y. 2008. Foot and mouth disease in the Borana pastoral system, southern Ethiopia and implications for livelihoods and international trade. Trop. Anim. Health Prod. 40(1), 29-38.

Samuel, A.R., Knowles, N.J. and MacKay, D.K. 1999. Genetic analysis of type $\mathrm{O}$ viruses responsible for epidemics of foot-and-mouth disease in North Africa. Epidemiol. Infec. 122(3), 529-538.

Sarker, S., Talukder, S., Haque, M.H., Islam, M.H. and Gupta, S.D. 2011. Epidemiological Study on Footand-Mouth Disease in Cattle: Prevalence and Risk 
Factor Assessment in Rajasthan, Bangladesh. Wayamba J. Anim. Sci. 71-73.

Valdazo-González, B., Knowles, N.J. and King, D.P. 2014. Genome Sequences of Foot-and-Mouth Disease Virus O/ME-SA/Ind-2001 Lineage from Outbreaks in Libya, Saudi Arabia, and Bhutan during 2013. Genome Announc. 2(2), e00242-14.

Vynnycky, E. and White, R.G. 2010. An introduction to Infectious Disease Modelling. Oxford University Press, Oxford, UK.

WRLFMD. 2014a. Genotyping report: FMDV type O. Country: Tunisia. FAO World Reference Library for Foot-and-Mouth Disease (WRLFMD), the Pirbright Institute, Surrey, United Kingdom:
http://www.wrlfmd.org/fmd_genotyping/2014/WR LFMD-2014-

00029\%200\%20Tunisia\%202014.pdf.

WRLFMD. 2014b. Genotyping report: FMDV type O. Country: Algeria. FAO World Reference Library for Foot-and-Mouth Disease (WRLFMD), the Pirbright Institute, Surrey, United Kingdom: http://www.wrlfmd.org/fmd_genotyping/2014/WR LFMD-201400028\%200\%20Algeria\%202014.pdf.

WRLFMD. 2016. The FAO World Reference Laboratory for Foot-and-Mouth Disease. http://www.wrlfmd.org/fmd_genotyping/africa/lib. htm. Accessed: 02/02/2016. 